\title{
In-hospital Outcome of Acute Coronary Syndrome Patients with on-Admission Hyponatremia
}

\author{
Mohammad Ali, Abdul Wadud Chowdhury, Khandker Md. Nurus Sabah, Md. Gaffar Amin, Sudhakar \\ Sarker, Bishnu Pada Saha, Md. Mashba-Ul-Haque, Jinat Farjana \\ Department of Cardiology, Dhaka Medical College Hospital, Dhaka.
}

\begin{abstract}
Key words:
Acute coronary

syndrome, $S T$

elevated

myocardial

ischemia, non-

ST elevated

myocardial

ischemia,

Hyponatremia.
\end{abstract}

\begin{abstract}
:
Background: Coronary artery disease is the commonest form of heart disease and the leading cause of morbidity and mortality throughout the world. Electrolytes imbalance can lead to increase in hospital mortality and morbidity in acute coronary syndrome patients. Our objective was to find out and to compare in-hospital outcome of patients presenting with acute coronary syndrome with or without onadmission hyponatremia.

Methods: A total of 336 patients were included in this study of which 59 patients were in group A (sodium level $<135 \mathrm{mmol} / \mathrm{l})$. Group A was subdivided in Group A1 ( $\left.\mathrm{Na}^{+}-134-130 \mathrm{mmol} / \mathrm{l}\right)$, Group A2 ( $\mathrm{Na}^{+}-120$ $129 \mathrm{mmol} / \mathrm{l}$ ), Group $\mathrm{A} 3\left(\mathrm{Na}^{+}-<120 \mathrm{mmol} / \mathrm{l}\right)$ and 277 patients were in group B (sodium level $>135 \mathrm{mmol} / \mathrm{l}$ ).

Results: On-admission hyponatremia was documented in $16.12 \%(59)$ of patients with acute coronary syndrome. Among them, 16 patients with acute anterior STEMI, 19 patients with acute inferior STEMI, 19 patients with NSTEMI and 5 patients with unstable angina. In this study, in hospital complications like acute heart failure (81.4\% vs. $29.2 \%, p<0.05)$, cardiogenic shock $(32.2 \%$ vs. $15.5 \%, p<0.05)$ and in hospital mortality $(6.8 \%$ vs. $1.1 \%, p<0.05)$ were significantly more in the patients with hyponatremia. The frequency of in hospital mortality, acute heart failure and arrhythmia progressively increased with increasing severity of hyponatremia. Logistic regression analysis showed low plasma sodium level was independently associated with in hospital mortality ( $\hat{a}=2.13, P=0.027, O R=8.388,95 \%$ CI 1.268 - 55.488).

Conclusion: In this study on-admission hyponatremia significantly associated with high in-hospital adverse outcome in acute coronary syndrome patients.
\end{abstract}

(Cardiovasc. j. 2019; 11(2): 139-146)

\section{Introduction:}

Acute coronary syndrome (ACS)—which includes ST-segment elevation myocardial infarction (STEMI), non-ST-segment elevation myocardial infarction (NSTEMI), and unstable angina-is an umbrella term for life-threatening situations that occur when the blood supply to the heart is blocked due to destabilization of a previously stable atherosclerotic plaque. ${ }^{1,2}$ ACS can also manifest as sudden cardiac arrest due to ischemia-induced tachyarrhythmias ${ }^{3}$

Hyponatremia commonly occurs in ACS and has been recognized as a worse prognostic indicator in patients with STEMI and NSTEMI. ${ }^{4-6}$ In addition, hyponatremia is also an independent predictor of adverse clinical outcomes in hospitalized patients due to decompensated heart failure 7

Hyponatremia is a well-known electrolyte disorder in hospitalized patients and it can make the prognosis worse depending on their background. ${ }^{8,9}$ In congestive heart failure (CHF), hyponatremia is associated with exaggerated activation of baroreceptor-mediated hormones, including arginine vasopressin (AVP), catecholamines and the renin-angiotensinaldosterone system. ${ }^{10,11}$ In particular, the primary mechanism is dilutional hyponatremia triggered by osmolality independent secretion of AVP. Baroreceptor mediated hormonal release

Address of correspondence: Dr. Mohammad Ali, Department of Cardiology, Dhaka Medical College, Dhaka, Bangladesh. Email: mdali_somc@yahoo.com

(C) 2018 authors; licensed and published by International Society of Cardiovascular Ultrasound, Bangladesh Chapter and Bangladesh Society of Geriatric Cardiology. This is an Open Access article distributed under the terms of the CC BY NC 4.0 (https:// creativecommons.org/licenses/by-nc/4.0). 
reflects the severity of heart failure, worsens cardiac remodeling in it-self, and thus could be one of the independent prognostic factors in CHF. ${ }^{12,13}$ In patients with acute myocardial infarction (AMI), baroreceptor- mediated hormonal activation is similar to that in patients with $\mathrm{CHF}$ and has a prognostic value. ${ }^{14}$

In ACS, due to activation of the Baroreceptor, there is activation of the sympathetic nervous system. This leads to release of hormones like vasopressin and also activation of reninangiotensin system. Magnitude of these neurohormonal changes is related to the severity of the myocardial damage. Hyponatremia is a reflection of these hormonal changes. So serum $\mathrm{Na}+$ level may be an indicator of the severity of STEMI. Whether hyponatremia (sodium $<135$ $\mathrm{mmol} / \mathrm{L}$ ) in the acute phase of ST-segment elevation myocardial infarction is just a marker of "more ill" patients or decreased sodium concentration is able to exert a direct adverse effect on the cardiovascular system is still unknown. ${ }^{15}$ Hyponatremia, which developed in the early phase of AMI, has also been recently advocated as an important prognostic factor in several studies. ${ }^{5,6,16}$ According to a past study, the plasma AVP level was significantly higher in patients who had a fatal outcome after AMI. ${ }^{17}$ The prevalence and importance of hyponatremia in patients with acute coronary syndrome in the era of primary intervention, however, have not yet been fully established.

The purpose of this study is to find out and to compare in hospital outcome (Acute LVF, Cardiogenic shock, Atrial fibrillation, Supra ventricular tachycardia, Ventricular tachycardia, Ventricular Fibrillation, AV block (2nd Degree/ 3rd degree), Post MI angina, Death) of patients with ACS with hyponatremia and those with ACS without hyponatremia who were observed in coronary care unit, DMCH, Dhaka.

\section{Methods:}

This prospective cross-sectional study was conducted over a period of 1 year from March 2016 to February 2017 at the Department of Cardiology, Dhaka Medical College Hospital, Dhaka. Samples were collected by purposive sampling technique. The estimated sample size was 463 . As the study was done in a single center within a limited period of time, so all the available sample within the study period was included in the study. The study complied with the Declaration of Helsinki. Prior ethical approval was obtained from the ethical review committee of Dhaka Medical College. Informed written consent was taken from each patient. All the acute coronary syndrome patients with or without hyponatremia presenting to CCU in $\mathrm{DMCH}$ within the study period were included in the study. Patients with history of any previous MI, PCI or CABG, valvular heart disease, congenital heart disease, primary myocardial or pericardial disease, acute on chronic heart failure, COPD, end stage renal disease, nephrotic syndrome, liver disease, chest infection and bronchogenic carcinoma, stroke, hypothyroidism and patients on diuretic therapy were excluded from the study. All the patients with acute coronary syndrome with or without hyponatremia admitted in the Department of Cardiology, $\mathrm{DMCH}$, within the study period and who fulfilled the other inclusion criteria and exclusion criteria included as study population and then the study population was grouped into 2 groups according to on-admission plasma sodium level. Patients with hyponatremia (Naz level $<135 \mathrm{mmol} / \mathrm{L}$ ) as Group A and patients with normal plasma sodium level (Naz level 135-145 mmol/L) as Group B. Group-A further categorized into three groups. Group-A1 (Naz level 130-134 mmol/L), Group-A2 $\left(\mathrm{Na}^{+}\right.$level 120 $129 \mathrm{mmol} / \mathrm{L})$ and Group-A3 $\left(\mathrm{Na}^{+}\right.$level $<120$ $\mathrm{mmol} / \mathrm{L})$. Information was collected through prepared proforma for each patient. Detailed history including history of present illness, past illness, drug history and personal history was taken. Relevant physical examination was done \& recorded. All the patients was treated with usual treatment protocol of the Institute and for each patient plasma sodium concentration are obtained on admission and other relevant routine investigations including blood glucose, CK-MB, blood urea, serum creatinine, serum lipid profile was also measured on admission. Both the groups were followed up till death or discharge. Parameters of outcome were recorded as per study protocol. All statistical analysis was performed using the statistical package for social 
science (SPSS) program, version 22 for Windows. Continuous parameters were expressed as mean $\pm \mathrm{SD}$ and categorical parameters as frequency and percentage. Comparisons between groups (continuous parameters) were done by Student's t test. Categorical parameters were compared by Chi-Square test. After hospital follow up, multivariate regression analysis was used to evaluate the influence of potential risk factors on the outcome. The significance of the results as determined in 95.0\% confidence interval and a value of $p<0.05$ will be consider to be statistically significant

\section{Results:}

This cross-sectional comparative study was conducted in the Department of Cardiology, Dhaka Medical College Hospital, Dhaka, over a period of one year from March 2016 to February 2017. The main objective of the study was to find out the In-hospital outcome of acute coronary syndrome patients with hyponatremia. A total of 336 adult patients with acute coronary syndrome included in the in the study which were admitted in the department of cardiology, DMCH within the study period.

In our study male patients were predominant and constitutes $71.2 \%$ in group $\mathrm{A}$ and $83.4 \%$ in group B. Maximum patients were in the age group 41-60 years, mean age was significantly more in group A than group B (63.6 $\pm 12.1 \mathrm{vs.}$ $54.5 \pm 11.1, \mathrm{p}<0.05)$. Highest percentage had the history of HTN (76.3\% vs. 57.4\%) followed by smoking (27.1\% vs. $41.4 \%)$, DL (18.6\% vs. $8.4 \%)$, Diabetes Mellitus (54.2\% vs.47.9\%) family history of CAD (22\% vs. $16.6 \%)$ in group A and group B respectively(Table-I).Comparison of hemodynamic profile between two groups revealed mean heart rate was $90.7 \pm 25.0$ vs. $85.2 \pm 19.8$, mean systolic blood pressure $112.5 \pm 27.3 \mathrm{vs} .117 .0 \pm 25.1$ and mean diastolic blood pressure $71.8 \pm 14.4$ vs.75.1 \pm 13.3 in group A than group B respectively and difference were statistically insignificant. Troponin-I and mean left ventricular ejection fraction were significantly low in group A than group B (14.6 \pm 16.2 vs. $8.8 \pm 114.1)$ and $(46.51 \pm 11.9 \mathrm{vs}$. $51.15 \pm 12.8)$. Serum creatinine ( $1.3 \pm 0.6 \mathrm{vs}$. $1.3 \pm 0.6)$ and blood sugar $(10.6 \pm 4.8$ vs. $9.7 \pm 4.5)$ insignificantly distributed between two groups. In our study hospital stay was significantly longer in group $\mathrm{A}$ in comparison to group $\mathrm{B}$ and that was11.3 \pm 3.80 vs. $6.34 \pm 2.69$ (Table-I).

Inthis study theincidence of acute anterior STEMI, acute inferior STEMI, NSTEMI and UA were insignificantly distributed between two groups (Table-II). In-hospital outcomes of acute coronary syndrome patients that death, acute heart failure, cardiogenic shock were more in Group A than Group B which is statistically significant $(p<0.05)$. Other parameters outcome were almost similarly distributed between two groups $(p>0.05)$ (Table-III).

Table-I

Demographic parameters of study population $(N=336)$.

\begin{tabular}{lccc}
\hline Variables & Group A & Group B & p value \\
\hline Age (Year) & $63.6 \pm 12.1$ & $54.5 \pm 11.1$ & $0.001 \mathrm{~s}$ \\
Male & $71.2 \%$ & $83.4 \%$ & $0.622 \mathrm{~ns}$ \\
HTN & $76.3 \%$ & $57.4 \%$ & $0.586 \mathrm{~ns}$ \\
DM & $54.2 \%$ & $47.9 \%$ & $0.583 \mathrm{~ns}$ \\
Dyslipidaemia & $18.6 \%$ & $8.4 \%$ & $0.354 \mathrm{~ns}$ \\
Smoking & $27.1 \%$ & $41.4 \%$ & $0.154 \mathrm{~ns}$ \\
Family H/O of CAD & $22 \%$ & $16.6 \%$ & $0.908 \mathrm{~ns}$ \\
Heart rate (beat/min) & $90.7 \pm 25.0$ & $85.2 \pm 19.8$ & $0.066 \mathrm{~ns}$ \\
Systolic BP(mmHg) & $112.5 \pm 27,3$ & $117.0 \pm 25.1$ & $0.145 \mathrm{~ns}$ \\
Diastolic BP(mmHg) & $71.8 \pm 14.4$ & $75.1 \pm 13.3$ & $0.087 \mathrm{~ns}$ \\
Troponin- I & $14.6 \pm 16.2$ & $8.8 \pm 114.1$ & $0.005 \mathrm{~s}$ \\
LVEF\% & $46.51 \pm 11.9$ & $51.15 \pm 12.8$ & $0.011 \mathrm{~s}$ \\
Random blood sugar & $10.6 \pm 4.8$ & $9.7 \pm 4.5$ & $0.193 \mathrm{~ns}$ \\
S. creatinine & $1.3 \pm 0.6$ & $1.3 \pm 0.6$ & $0.511 \mathrm{~ns}$ \\
Hospital stay (days) & $11.3 \pm 3.80$ & $6.34 \pm 2.69$ & $0.001 \mathrm{~s}$ \\
\hline
\end{tabular}

S- Significant, ns- not significant. 
Table-II

Comparison of clinical diagnosis between two groups $(N=336)$

\begin{tabular}{|c|c|c|c|c|c|}
\hline \multirow[t]{2}{*}{ Diagnosis } & \multicolumn{2}{|c|}{$\begin{array}{c}\text { Group A } \\
(\mathrm{n}=59)\end{array}$} & \multicolumn{2}{|c|}{$\begin{array}{c}\text { Group B } \\
(\mathrm{n}=277)\end{array}$} & \multirow[t]{2}{*}{$\mathrm{p}$ value } \\
\hline & No. & $\%$ & No. & $\%$ & \\
\hline Acute anterior STEMI & 16 & 27.1 & 82 & 29.6 & $0.703 \mathrm{~ns}$ \\
\hline Acute inferior STEMI & 19 & 32.2 & 82 & 29.6 & $0.692 \mathrm{~ns}$ \\
\hline NSTEMI & 19 & 32.2 & 60 & 21.7 & $0.082 \mathrm{~ns}$ \\
\hline Unstable angina & 5 & 8.5 & 53 & 19.1 & $0.075 \mathrm{~ns}$ \\
\hline Total & 59 & 100.0 & 277 & 100.0 & \\
\hline
\end{tabular}

S- Significant, ns- not significant

Table-III

Comparison of in-hospital adverse outcome between two groups $(N=366)$.

\begin{tabular}{|c|c|c|c|c|c|}
\hline \multirow[t]{2}{*}{ In-hospital outcome } & \multicolumn{2}{|c|}{$\begin{array}{c}\text { Group A } \\
(\mathrm{n}=59)\end{array}$} & \multicolumn{2}{|c|}{$\begin{array}{c}\text { Group B } \\
(\mathrm{n}=277)\end{array}$} & \multirow[t]{2}{*}{$p$ value } \\
\hline & No. & $\%$ & No. & $\%$ & \\
\hline Death & 4 & 6.8 & 3 & 1.1 & $0.005 \mathrm{~s}$ \\
\hline Acute heart failure & 48 & 81.4 & 81 & 29.2 & $<0.001 \mathrm{~s}$ \\
\hline Cardiogenic shock & 19 & 32.2 & 43 & 15.5 & $0.003 \mathrm{~s}$ \\
\hline Post MI angina & 3 & 5.1 & 5 & 1.8 & $0.133 \mathrm{~ns}$ \\
\hline Cardiac arrest & 1 & 1.7 & 1 & 0.4 & $0.226 \mathrm{~ns}$ \\
\hline Arrhythmia (AF, VT, VF) & 9 & 15.3 & 27 & 9.7 & $0.214 \mathrm{~ns}$ \\
\hline Conduction defect & 4 & 6.8 & 9 & 3.2 & $0.202 \mathrm{~ns}$ \\
\hline
\end{tabular}

S- Significant, ns- not significant

This study showed in-hospital mortality $(0.0 \%$ vs. $10.7 \%$ vs. $40.0 \%)$, acute heart failure $(65.4 \%$ vs. $92.9 \%$ vs. $100 \%)$ and arrhythmia (15.4\% vs. $7.1 \%$ vs. $60.0 \%$ ) increased significantly (Table IV). With increasing the severity of hyponatremia, in- hospital mortality and acute heart failure increased significantly in STEMI in-comparison with NSTEMI and Unstable angina (Table V) (Table VI).

Logistic regression analysis of in-hospital mortality with independent risk factors, independent variable plasma sodium level was significantly associated with in-hospital mortality ( $\hat{\mathrm{a}}=2.13, \mathrm{P}=0.027$, OR $=8.388,95 \%$ CI 1.268 55.488). Other independent variables not significantly associated with in-hospital mortality (Table VII).Logistic regression analysis of acute heart failure with independent risk factors, independent variable plasma sodium level, male sex, hypertension, ejection fraction and hyponatremia were significantly associated with acute heart failure. Other independent variables not significantly associated with inhospital mortality (Table VIII).

\section{Table-IV}

Comparison of in-hospital adverse outcome with severity of hyponatremia $(N=59)$.

\begin{tabular}{lcccc}
\hline In-hospital outcome & \multicolumn{3}{c}{ Group A } & p value \\
\cline { 2 - 4 } & $\begin{array}{c}\text { Group A1 } \\
(\mathrm{n}=26)\end{array}$ & $\begin{array}{c}\text { Group A2 } \\
(\mathrm{n}=28)\end{array}$ & $\begin{array}{c}\text { Group A3 } \\
(\mathrm{n}=5)\end{array}$ \\
\hline Death & 0.0 & $3(10.7)$ & $2(40.0)$ & $0.011^{\mathrm{s}}$ \\
Acute heart failure & $17(65.4)$ & $26(92.9)$ & $5(100.0)$ & $0.019^{\mathrm{s}}$ \\
Cardiogenic shock & $7(26.98)$ & $12(42.9)$ & $0(0.0)$ & $0.125^{\mathrm{ns}}$ \\
Post MI angina & $2(7.7)$ & $1(3.6)$ & 0 & $0.681^{\mathrm{ns}}$ \\
Arrhythmia (AF, VT, VF) & $4(15.4)$ & $2(7.1)$ & $3(60.0)$ & $0.010^{\mathrm{s}}$ \\
Conduction defect & $1(3.8)$ & $3(10.7)$ & 0.0 & $0.496^{\mathrm{ns}}$ \\
\hline
\end{tabular}


Table-V

Comparison of In-hospital mortality in different type of ACS with increasing severity of hyponatremia $(n=59)$.

\begin{tabular}{lcccc}
\hline Type of ACS & \multicolumn{3}{c}{ Group A (n=59) } & p value \\
\cline { 2 - 5 } & $\begin{array}{c}\text { Group A1 } \\
(130-\end{array}$ & $\begin{array}{c}\text { Group A2 } \\
(120-\end{array}$ & $\begin{array}{c}\text { Group A3 } \\
(<120 \mathrm{mmol} / \mathrm{l})\end{array}$ & \\
\hline STEMI $(\mathrm{n}=35)$ & $(\mathrm{n}=17)$ & $(\mathrm{n}=16)$ & $(\mathrm{n}=2)$ \\
Death & 0.0 & $3(18.5)$ & $2(100.0)$ & $0.043^{\mathrm{s}}$ \\
NSTEMI $(\mathrm{n}=19)$ & $(\mathrm{n}=6)$ & $(\mathrm{n}=11)$ & $(\mathrm{n}=2)$ & \\
Death & $0(0.0)$ & $1(9.1)$ & $1(50.0)$ & $0.133^{\mathrm{ns}}$ \\
U. Angina $(\mathrm{n}=5)$ & $(\mathrm{n}=3)$ & $(\mathrm{n}=1)$ & $(\mathrm{n}=1)$ & - \\
Death & & 0 & 0 & 0 \\
\hline
\end{tabular}

Table-VI

Comparison of In-hospital acute heart failure in different type of ACS with severity of hyponatremia $(n=59)$.

\begin{tabular}{lcccc}
\hline Type of ACS & \multicolumn{3}{c}{ Group A } & p value \\
\cline { 2 - 4 } & Group A1 & Group A2 & Group A3 & \\
\hline STEMI $(\mathrm{n}=35)$ & $(\mathrm{n}=17)$ & $(\mathrm{n}=16)$ & $(\mathrm{n}=2)$ & \\
$\quad 11(64.7)$ & $16(100.0)$ & $2(100.0)$ & $0.022^{\mathrm{s}}$ \\
LVF & $(\mathrm{n}=6)$ & $(\mathrm{n}=11)$ & $(\mathrm{n}=2)$ & \\
NSTEMI $(\mathrm{n}=19)$ & $4(66.7)$ & $10(62.5)$ & $2(100.0)$ & $0.344^{\mathrm{ns}}$ \\
LVF & $(\mathrm{n}=3)$ & $(\mathrm{n}=1)$ & $(\mathrm{n}=1)$ & \\
Unstable angina $(\mathrm{n}=5)$ & $2(66.7)$ & $0(0.0)$ & $1(100.0)$ & $0.329^{\mathrm{ns}}$ \\
$\quad$ LVF & & &
\end{tabular}

S- Significant, ns- not significant

Table-VII

Logistic regression analysis of in-hospital mortality with independent risk factors in patients with ACS $(N=336)$.

\begin{tabular}{lcccccc}
\hline Independent risk factor & $\beta$ & S.E. & P value & Odd ratio & \multicolumn{2}{c}{$95 \%$ C.I. for EXP(B) } \\
\cline { 5 - 7 } & & & & & Lower & Upper \\
\hline Age & 0.01 & 0.04 & .788 & 1.010 & .940 & 1.086 \\
Sex- Male & -0.71 & 0.90 & .433 & 0.493 & .084 & 2.893 \\
Hypertension & 17.09 & 2900 & .995 & 263.0 & .000 &.- \\
Diabetes & -0.72 & 0.96 & .451 & 0.486 & .074 & 3.172 \\
Obesity & -0.32 & 0.63 & .607 & 0.723 & .211 & 2.482 \\
TroponinIng/ml & -0.03 & 0.02 & .146 & 0.971 & .932 & 1.010 \\
Ejection fraction (\%) & 0.06 & 0.05 & .164 & 1.066 & .974 & 1.167 \\
Hyponatremia & 2.13 & 0.96 & $.027^{*}$ & 8.388 & 1.268 & 55.488 \\
\hline
\end{tabular}


Table-VIII

Logistic regression analysis of acute heart failure with independent risk factors in patients with ACS $(n=336)$.

\begin{tabular}{lcccccc}
\hline Independent risk factors & $\beta$ & S.E. & $\mathrm{p}$ value & Odd ratio & \multicolumn{2}{c}{$95 \%$ C.I. for EXP(B) } \\
\cline { 5 - 7 } & & & & & Lower & Upper \\
\hline Age & .000 & .012 & .994 & 1.000 & .978 & 1.023 \\
Sex- Male & -1.051 & .351 & $.003^{*}$ & .349 & .176 & .695 \\
Hypertension & .659 & .293 & $.024^{*}$ & 1.932 & 1.089 & 3.429 \\
Diabetes & .346 & .290 & .232 & 1.413 & .801 & 2.494 \\
Obesity & -.331 & .248 & .181 & .718 & .442 & 1.167 \\
Troponin I ng/ml & -.015 & .009 & .094 & .985 & .968 & 1.003 \\
Ejection fraction (\%) & .056 & .011 & $.000^{*}$ & 1.058 & 1.034 & 1.081 \\
Hyponatremia & 2.451 & .412 & $.000^{*}$ & 11.598 & 5.174 & 26.000 \\
\hline
\end{tabular}

\section{Discussion:}

This prospective comparative observational study was conducted in the coronary care unit (CCU) of Department of Cardiology, Dhaka Medical College Hospital, Dhaka, over a period of one year from March 2016 to February 2017. The main objective of the study was to find and to compare in-hospital outcome of acute coronary syndrome patients with on-admission hyponatremia admitted in Dhaka Medical College Hospital during this study period.

For those purpose 336 patients with acute coronary syndrome were included according to exclusion and inclusion criteria of which 98 patients were diagnosed as anterior STEMI, 101 patients were diagnosed as inferior STEMI. 79 patients were diagnosed as NSTEMI and 58 patients were diagnosed as unstable angina.

Blood samples were obtained during hospital admission for measurement of plasma sodium. Depending of plasma sodium level these patients were divided into 2 groups. Among 366 patients 59 patients were in group A when plasma sodium

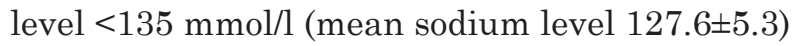
and 277 patients were in groups B when plasma sodium level $\geq 135 \mathrm{mmol} / \mathrm{l}$ (mean plasma sodium level 140.3 \pm 3.5 ). STEMI, NSTEMI and unstable angina patients were similarly distributed between two groups.

In our study male were predominant in both groups but significantly more in group B which constituted $71.2 \%$ vs. $83.4 \%$. Goldberg et al. ${ }^{5}$ had similar pattern of sex distribution in which male was $71 \%$ and $80 \%$ in group A and group B respectively. Maximum patients were in the age group 51-60 years. Mean age of our patients was $62.6 \pm 12$ years in group A (range $35-100$ years) and 54.5 \pm 11.1 years in group B (range 28-85 years). Similar pattern of age distribution was reported by Goldberget al. ${ }^{11}$ which was $62 \pm 12$ years in group A and $59 \pm 12$ years in group B.

The frequency of hyponatremia in our study was $16.12 \%$. The frequency of hyponatremia in our study is higher than the prevalence observed by Qing Tang et al. in a study with Chinese population with STEMI and which was $13.1 \% .{ }^{17}$ This difference between two studies may be due to inclusion of NSTEMI and UA and difference in size and food habit. Lazzeriet al. observed $23.2 \%$ incidence of hyponatremia in acute STEMI patients. ${ }^{18}$ Singla et al. ${ }^{3}$ showed the incidence of hyponatremia in non-STEMI patients was $23.1 \%$.

ACS patients with hyponatremia (Group A) were categorized into 3 subgroups in our study. Group A1 included those patients with plasma sodium level $130-134 \mathrm{mmol} / \mathrm{l}$. Patients with plasma sodium level $120-129 \mathrm{mmol} / \mathrm{l}$ and $<120 \mathrm{mmol} / \mathrm{l}$ were in group A2 and group A3 respectively. 26(44.1\%) patients were in sub-group A1 and $28(47.5 \%), 5(8 \%)$ patients were in sub groupA2, sub-group A3 respectively. Aziz et al. ${ }^{19}$ conducted a study in Bangladesh showed 50\%, 20\% and 15\% hyponatremia in sub group A1, sub-group A2, sub-group A3 respectively.

Among the important risk factor of coronary artery disease, hypertension was 45 (76.3\%) vs. 132 (47.4\%), Diabetes mellitus was $32(54.2 \%)$ 
vs. 105 (37.9\%), Dyslipidemia was 11 (18.6\%) vs. 32 (1.6\%), Smoking was 16 (7.1\%) vs. 87 (31.4\%), Family history of coronary artery disease was $13(22 \%)$ vs. $46(16.6 \%)$ and obesity was $23(39 \%)$ vs. $117(42.2 \%)$ observed between two groups. Tada et al. showed similar pattern of risk factors in his study which were hypertension $21(72 \%)$ vs. $70(63 \%)$, diabetes mellitus $11(38 \%)$ vs. 47 (42\%) Dyslipidemia 19 (66\%) vs. 62 (56\%), But Family history of coronary artery disease and obesity were not assess in that study. ${ }^{16}$

The hemodynamic status of the patients of two groups showed no significant difference. The heart rate, systolic blood pressure and diastolic blood pressure between two groups were similar. Mean value of troponin I was significantly more in hyponatremia patients $(\mathrm{p}<0.005)$. This finding is supported by Singlaetal. ${ }^{3}$ In their study of 1478 patients with NSTEMI; they observed a significant correlation between on-admission hyponatremia and high troponin level. Other biochemical parameters were almost similarly distributed between two groups ( $p>0.05$ ).

In this study, hyponatremia patients had an inhospital mortality rate almost 1.3 times greater than that of patients with normal serum sodium level. 4(6.8\%) patients died in group $\mathrm{A}$ and $3(1.1 \%)$ patients died in group B. Lazzeri et al. ${ }^{18}$ showed in-hospital mortality was $7.7 \%$ vs. $3.8 \%$ in STEMI patients with hyponatremia. Singla et al. ${ }^{3}$ showed in-hospital mortality was $13.8 \%$ vs. $7.5 \%$ in non-STEMI with hyponatremia and Goldberg et al. ${ }^{11}$ observed in -hospital mortality was $24.1 \%$ vs. $9.0 \%$ in acute STEMI patients.

In our study severity of acute heart failure (Kilip class III or more) significantly more in group A compared to group B $(57.6 \%$ vs. $22.0 \%, \mathrm{p}<.001)$. Tada et al. ${ }^{16}$ shown Kilip class $\geq$ III was $18 \%$ vs. $15 \%$ between two groups. The severity of acute left ventricular failure was proportionately increasing with decreasing level of hyponatremia. The prevalence of acute heart failure was significantly more among the STEMI patients with hyponatremia in comparison to patients with NSTEMI and Unstable Angina.

In this study left ventricular ejection fractions was significantly low in hyponatremia patients in comparison to patients with normal serum sodium level. Mean ejection fractions was $46.5 \pm 11.6 \%$ in group A and $51.15 \pm 12.8 \%$ in group $\mathrm{B}$ which showed significant difference between two groups. ( $p=0.011$ ). Qing Tang et al. ${ }^{17}$ showed the LV ejection fraction was $51.65 \pm 9.05 \%$ vs. $54.83 \pm 8.95 \%$ between two groups of Chinese patients with STEMI. Goldberg et al. ${ }^{11}$ showed $47 \pm 13 \%$ vs. $42 \pm 13 \%$ between two groups STEMI patients.

In our study duration of hospital stay was significantly higher in patients with hyponatremia in comparison to normal plasma sodium level. Mean duration of hospital stay in hyponatremia patients was $11.3 \pm 3.80$ vs. 6.34 \pm 2.69 . Tada et al. ${ }^{16}$ showed 24.6 vs. 15.2 between two groups which was also significant.

Among the others adverse outcome, cardiogenic shock (32.2\% vs. $15.5 \%$ ) was significantly higher $(\mathrm{p}=0.003)$ in group A in comparison to group B. However, post MI angina (5.1\% vs. $1.8 \%)$, arrhythmia (15.3\% vs. $9.7 \%)$ and conductive defect $(6.8 \%$ vs. $3.2 \%)$ were higher but not significant between two groups. In this study inhospital mortality (0.0 vs. 10.7 vs. 40.0$)$, acute heart failure (65.4 vs. 92.9 vs. 100.0) and arrhythmia (14.4 vs. 7.1 vs. 60.0$)$ significantly increased with increasing severity of hyponatremia respectively in group A1, group A2, group A3. Among the different types of acute coronary syndrome, in-hospital mortality and acute heart failure were significantly higher in STEMI in comparison to NSTEMI and UA.

In present study logistic regression analysis of in-hospital mortality with independent risk factors showed low plasma sodium level was significantly associated with in-hospital mortality ( $\hat{\mathrm{a}}=2.13, \mathrm{P}=0.027, \mathrm{OR}=8.388,95 \% \mathrm{CI}$ 1.268-55.488). In case of acute heart failure, hyponatremia with other independent risk factors such as male sex, hypertension, and ejection fraction were significantly associated with acute heart failure.

\section{Limitations:}

Although the result of this study is statistically significant and support the hypothesis, there were some major limiting factors which might affect the results. The study was conducted in a single tertiary care hospital with small sample 
size which may not represent the general population. All the patients with acute coronary syndrome with or without hyponatremia were not included due to different contraindications and co-morbid conditions such as chronic renal failure, history of previous MI, stroke. The study did not have the scope of long term follow up, so morbidity or complication in the long run could not be determined.

\section{Conclusion:}

This study showed patients with on-admission hyponatremia have more adverse in-hospital outcome in comparison to patients with normal plasma sodium level. In-hospital mortality, acute LVF, cardiogenic shock was frequently occurred in patients with hyponatremia. With increasing severity of hyponatremia, the incidence of inhospital adverse outcome was also increased and it was significant in STEMI patients. The incidence of in-hospital mortality and acute heart failure increased in STEMI in comparison to NSTEMI and unstable angina among the hyponatremia patients with increasing the severity of hyponatremia. This study suggested that the presence of on-admission hyponatremia should alert physicians to an increased risk of morbidity and mortality. This sub-group of the patients needs more aggressive treatment, including appropriate utilization of cardiovascular diagnostic tests and therapeutics used in current cardiovascular care to optimize outcomes.

\section{Conflict of Interest - None.}

\section{References:}

1. Ohman EM, Granger CB, Harrington RA, Lee KL. Risk stratification and therapeutic decision making in acute coronary syndromes. JAMA 2000; 284: 876-878.

2. Morrow DA, Antman EM, Charlesworth A, et al. TIMI risk score for ST-elevation myocardial infarction: a convenient, bedside, clinical score for risk assessment at presentation. Circulation 2000; 102: 2031-2037.

3. Singla I, Zahid M, Good CB, Macioce A, Sonel AF. Effect of hyponatremia $(<135 \mathrm{mEq} / \mathrm{L})$ on outcome in patients with non-ST elevation acute coronary syndrome. Am J Cardiol 2007; 100: $406-408$.

4. Hamaguchi S, Kinugawa S, Tsuchihashi-Makaya M, Matsushima S, Sakakibara M, Ishimori N, Goto D, Tsutsui $\mathrm{H}$. Hyponatremia is an independent predictor of adverse clinical outcomes in-hospitalized patients due to worsening heart failure. J Cardiol 2014; 63: 182-188.
5. Clayton JA, Le Jeune IR, Hall IP. Severe hyponatraemia in medical in-patients: Aetiology, assessment and outcome. QJM 2006: 99: 505 - 511 .

6. Upadhyay A, Jaber BL, Madias NE. Incidence and prevalence of hyponatremia. Am J Med 2006; 119: S30 S35.

7. Szatalowicz VL, Arnold PE, Chaimovitz C, Bichet D, Berl T, Schrier RW. Radioimmunoassay of plasma arginine vasopressin in hyponatremic patients with congestive heart failure. N Engl J Med 1981; 305: 263 - 266.

8. Nakamura T, Funayama H, Yoshimura A, Tsuruya Y, Saito M, Kawakami M, et al. Possible vascular role of increased plasma arginine vasopressin in congestive heart failure. Int J Cardiol 2006; 106: 191 - 195.

9. Ferrari R, Ceconi C, Campo G, Cangiano E, Cavazza C, Secchiero P, et al. Mechanisms of remodelling: A question of life (stem cell production) and death (myocyte apoptosis). Circ J 2009; 73: $1973-1982$.

10. Rossi J, Bayram M, Udelson JE, Lloyd-Jones D, Adams $\mathrm{KF}$, Oconnor CM, et al. Improvement in hyponatremia during hospitalization for worsening heart failure is associated with improved outcomes: Insights from the Acute and Chronic Therapeutic Impact of a Vasopressin Antagonist in Chronic Heart Failure (ACTIV in CHF) trial. Acute Card Care 2007; 9: $82-86$.

11. Goldberg A, Hammerman H, Petcherski S, Zdorovyak A, Yalonetsky S, Kapeliovich M, et al. Prognostic importance of hyponatremia in acute ST-elevation myocardial infarction. Am J Med 2004; 117: 242 - 248.

12. Chiara Lazzeri $\mathrm{C}$, Valente $\mathrm{S}$, Chiostri $\mathrm{M}$, Attanà $\mathrm{P}$, Picariello C, Gensini GF. Usefulness of Hyponatremia in the Acute Phase of ST-Elevation Myocardial Infarction as a Marker of Severity. Am J Cardiol 2012; 110: 1419-1424.

13. Goldberg A, Hammerman H, Petcherski S, Nassar M, Zdorovyak A, Yalonetsky S, et al. Hyponatremia and long term mortality in survivors of acute ST elevation myocardial infarction. Arch Intern Med 2006; 166: 781-786.

14. Klopotowski M, Kruk M, Przyluski J, Kalinczuk L, Pregowski J, Bekta P, et al. Sodium level on admission and in-hospital outcomes of STEMI patients treated with primary angioplasty: the ANIN Myocardial Infarction Registry. Med Sci Monit 2009; 15: CR477-483

15. Schaller MD, Nussberger J, Feihl F, Waeber B, Brunner HR, Perret C, et al. Clinical and hemodynamic correlates of elevated plasma arginine vasopressin after acute myocardial infarction. Am J Cardiol 1987; 60: 1178-1180.

16. Tada Y, Nakamura T, Funayama H, Sugawara Y, Ako J, Ishikawa SE, et al. Early development of hyponatremia implicates short- and long-term outcomes in ST-elevation acute myocardial infarction. Circ J 2011; 75:. 1927 - 1933.

17. Tang Q, Hua Q. Relationship between Hyponatremia and In-hospital Outcomes in Chinese Patients with ST-Elevation Myocardial Infarction. Intern Med 2011; 50: 969-974.

18. Lazzeri JJ, Kilonzo K, Nistico A, Yeates K. Management of hyponatremia. CMAJ 2014; 186(8): E281-286.

19. Aziz M, Ullah M, Azam MG, Hossain M. In-hospital Outcome of Acute ST Elevation Myocardial Infarction with Hyponatraemia. Cardiovasc j 2009; 2(1): 37-42. 